Supplement of:

\title{
Organic aerosol source apportionment in Zurich using extractive electrospray ionization time-of-flight mass spectrometry (EESI-TOF): Part I, biogenic influences and
}

5 day/night chemistry in summer

Giulia Stefenelli et al.

Correspondence to: Jay G. Slowik (jay.slowik@psi.ch)

a)

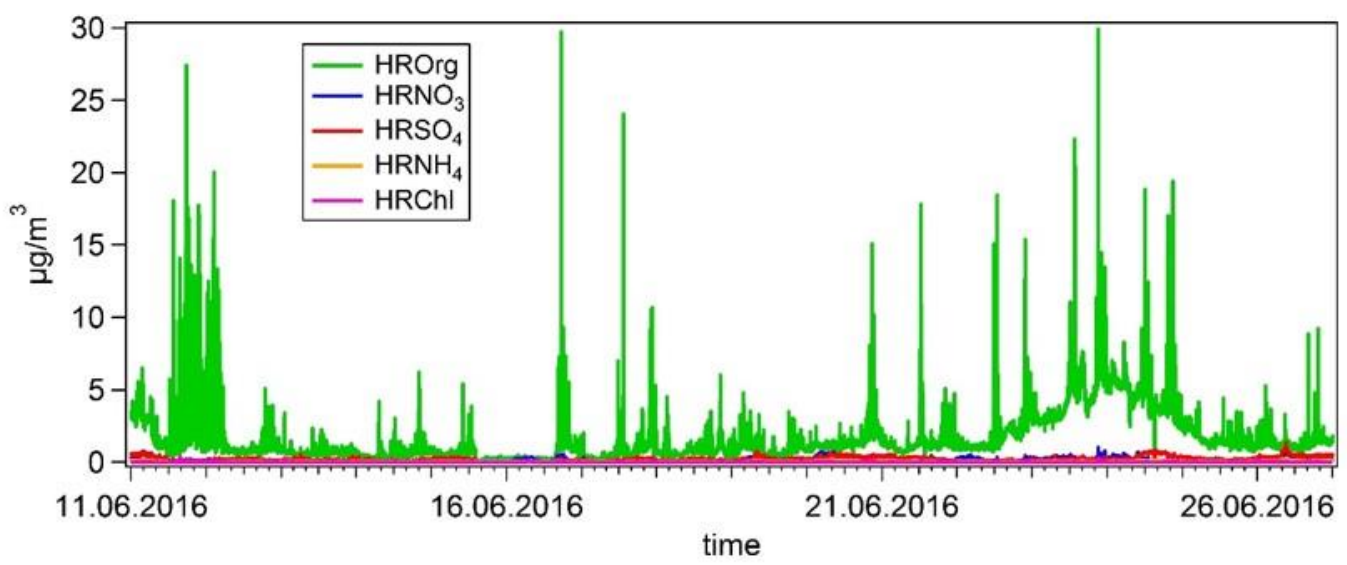

b)

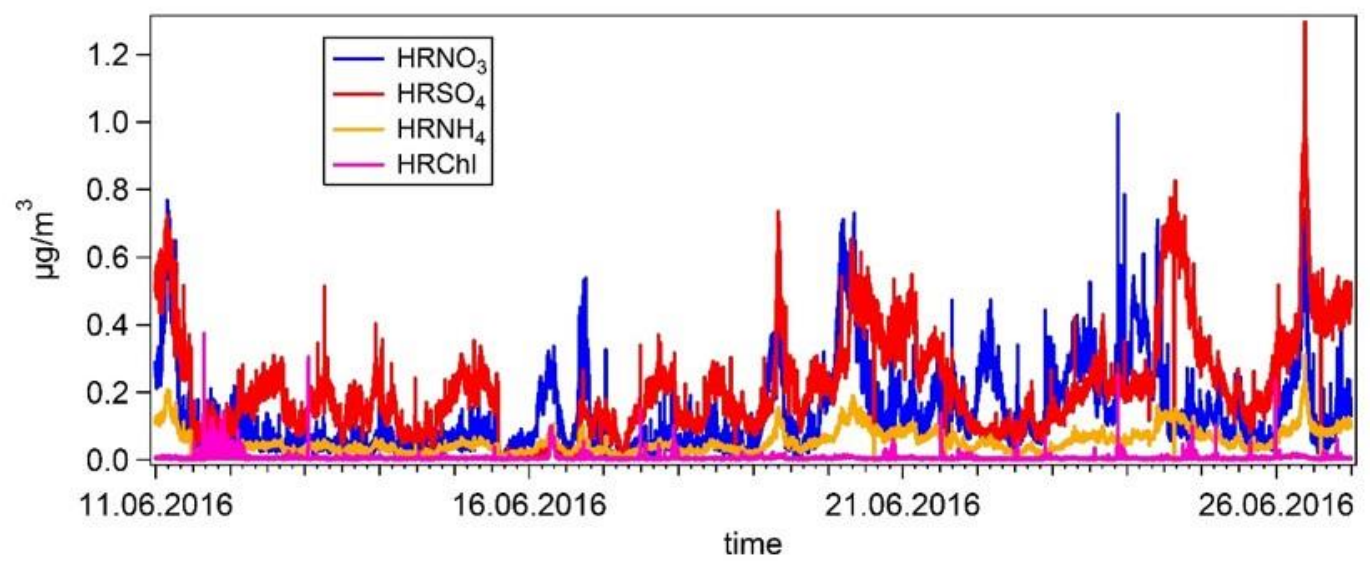

Figure S1. High resolution AMS time-series of all measured species a) and without organics b). 


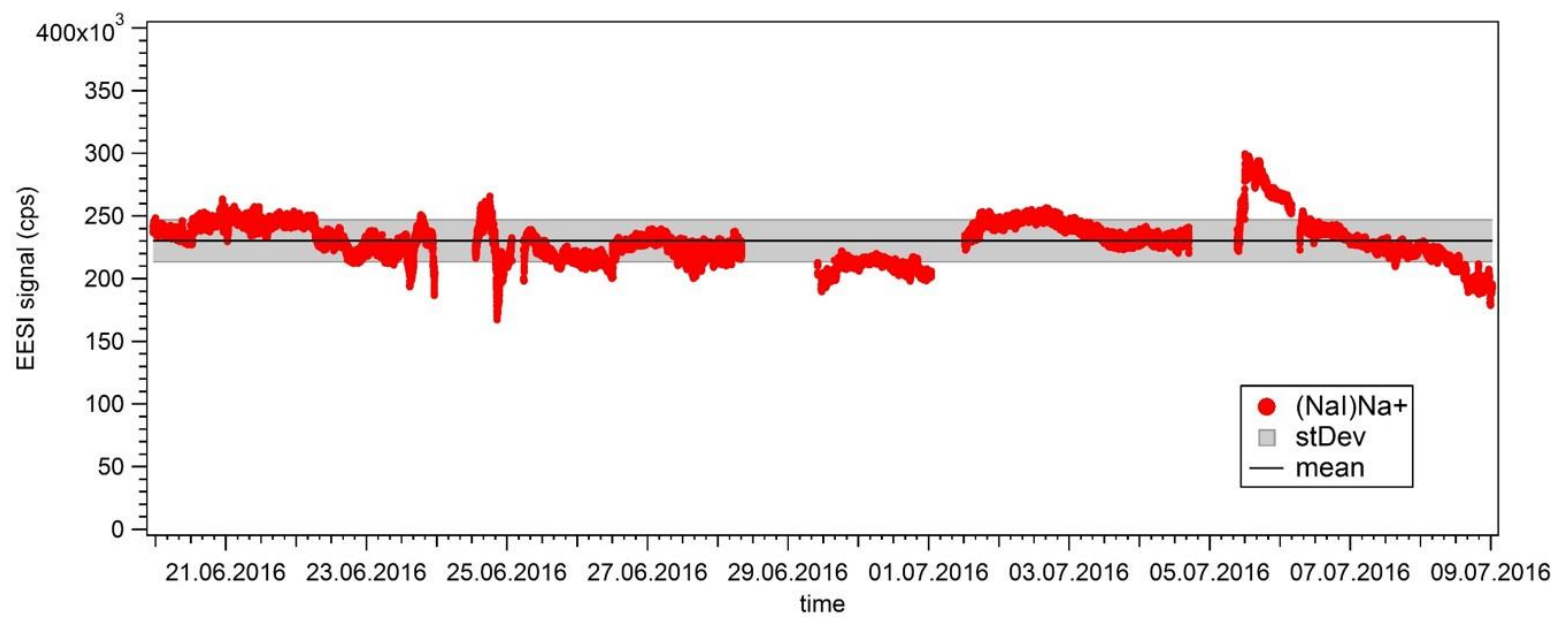

Figure S2. Time-serie of $(\mathrm{NaI}) \mathrm{Na}^{+}$including average and standard deviation in cps.

a)

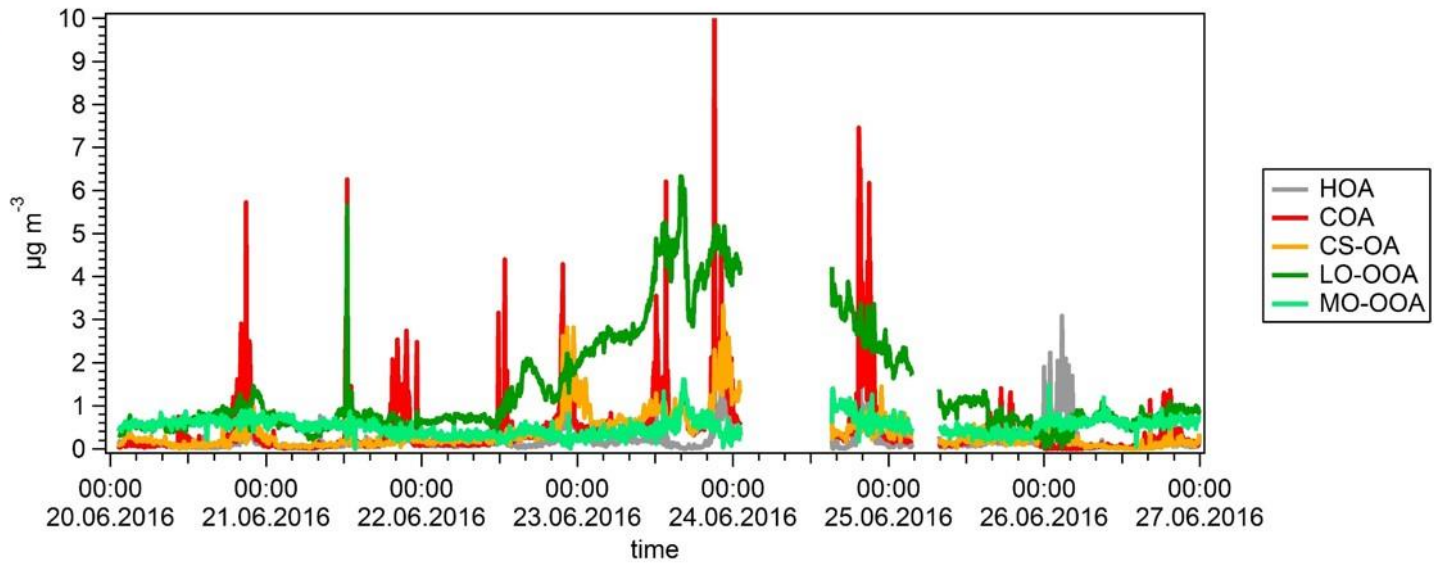

b)

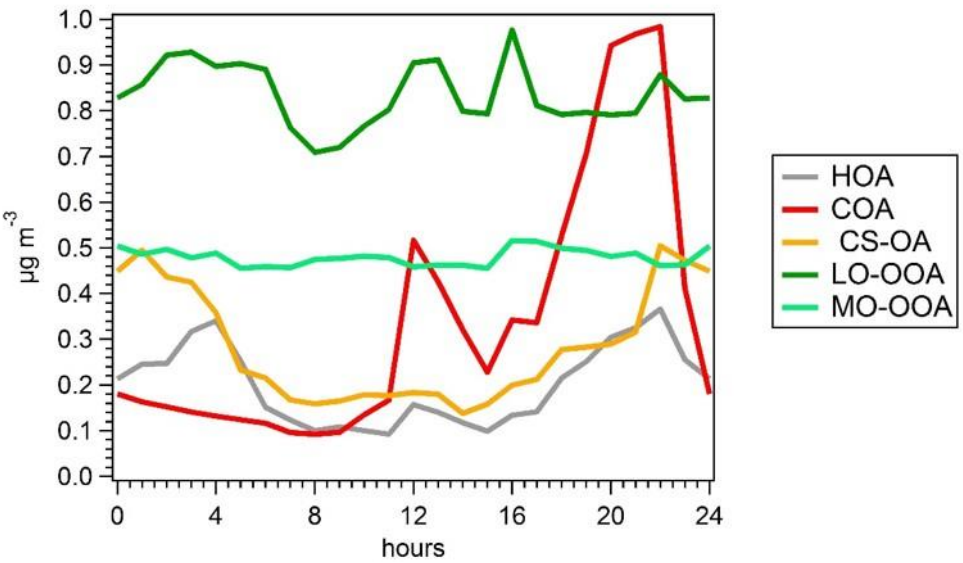

$5 \quad$ Figure S3. AMS PMF factors time-series a) and diurnal profiles b). 
a)

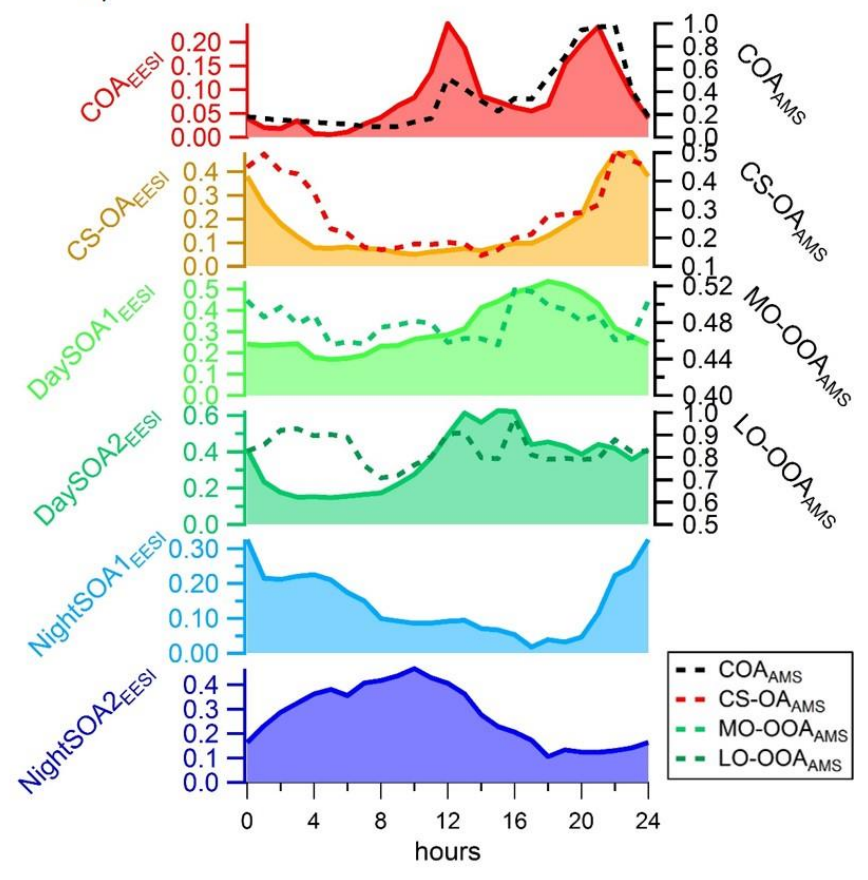

b)

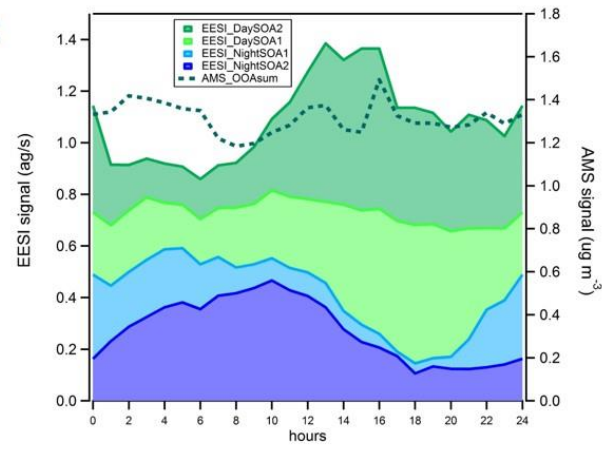

c)

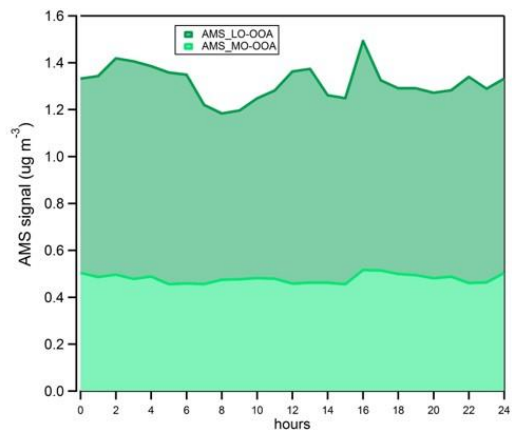

Figure S4. a) EESI-TOF PMF factor diurnals for the overlapping period only on the left axis (ag s${ }^{-1}$ ) and counterpart diurnal from AMS PMF analysis on the right axis $\left(\mu \mathrm{g} \mathrm{m}^{-3}\right)$. b) Stacked diurnal variations of the EESITOF SOA factors (left axis) and the AMS OOA sum (right axis). c) Stacked diurnal variations of the AMS OOA factors. 
a)

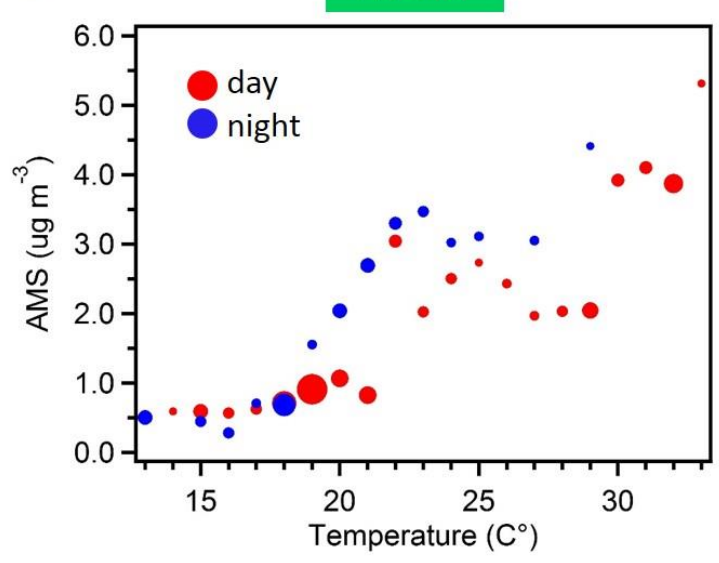

b)

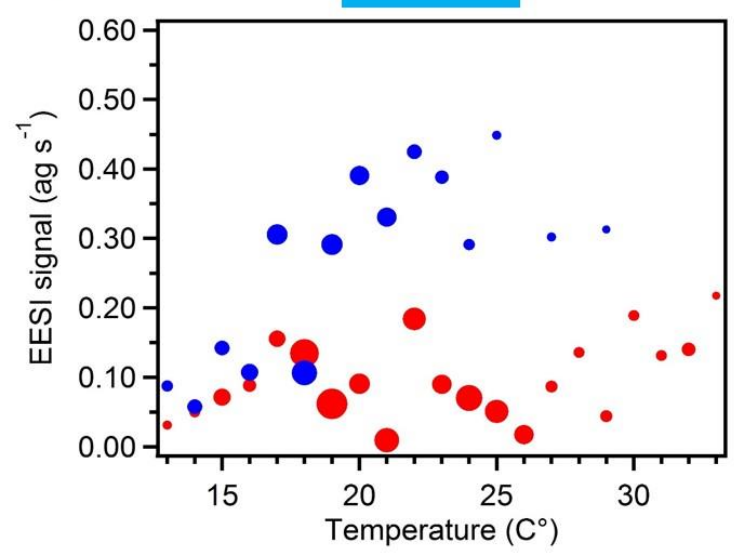

MO-OOA

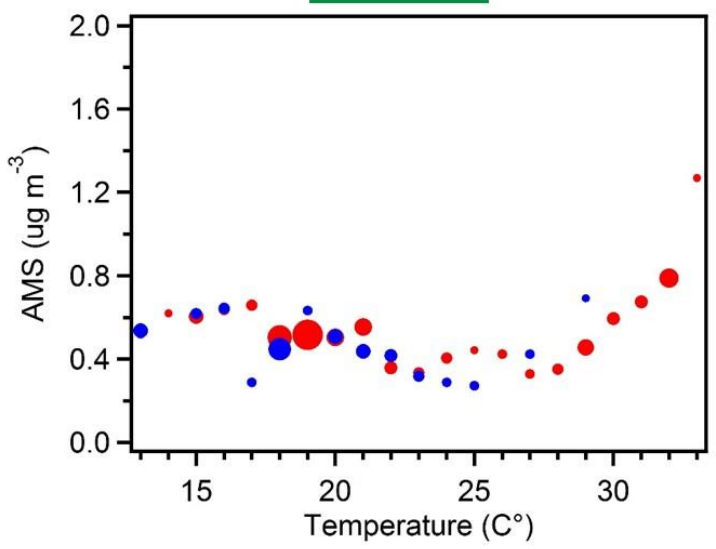

NightSOA2

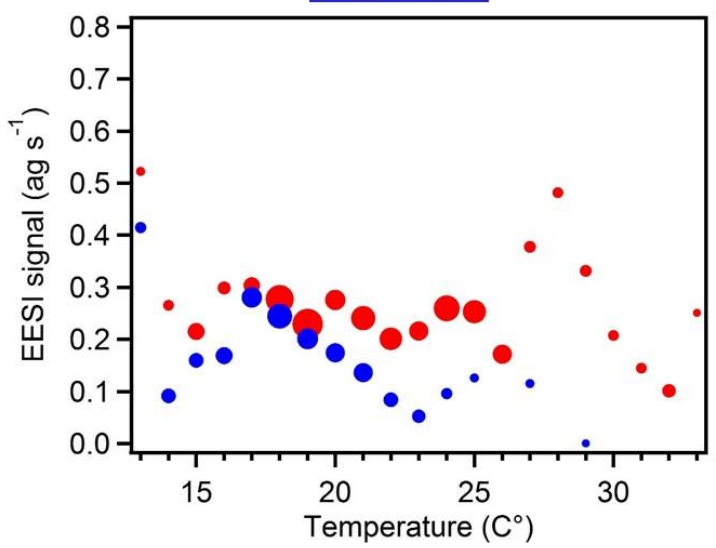

Figure S5. Correlation of a) AMS OOA factors and b) EESI-TOF NightSOA factors with ambient temperature $\left(\mathrm{C}^{\circ}\right)$ during the measurements period. The data are color-coded according to day (red) and night (blue) measurements time, they are grouped in temperature bins of $1 \mathrm{C}^{\circ}$ and the size of the dots corresponds to the number of points considered. Data corresponding to precipitation time has been discarded. 


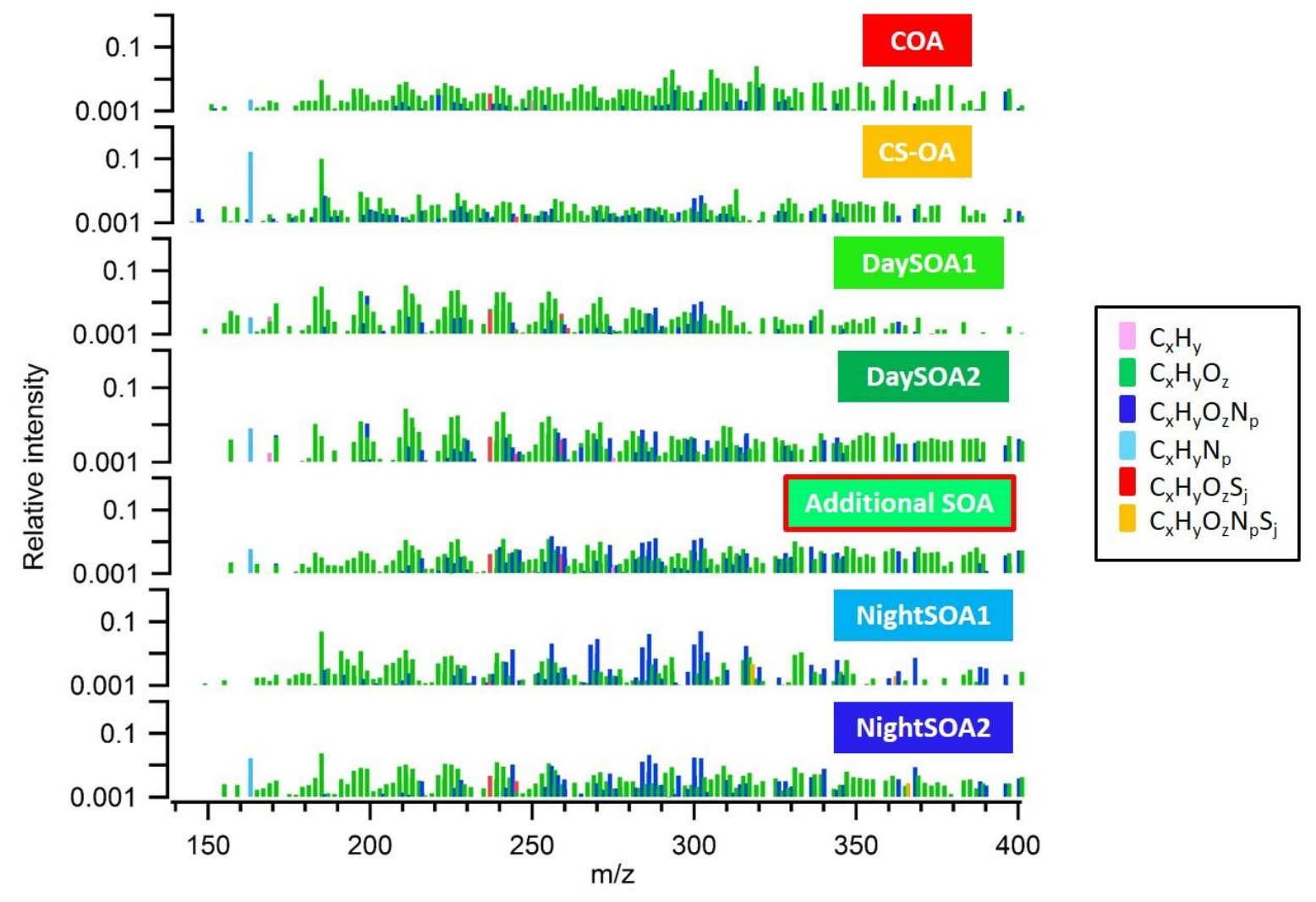

Figure S6. Mass spectra (log scale) of the seven identified OA EESI-TOF PMF factors, color-coded according to their chemical families for the 7-factor solution. All peaks are first weighted according to their molecular weight and and then normalized such that the sum of each spectrum is 1 . The final solution is based on 6 factor, where the additional SOA factor is combined with the other daytime SOA factors.
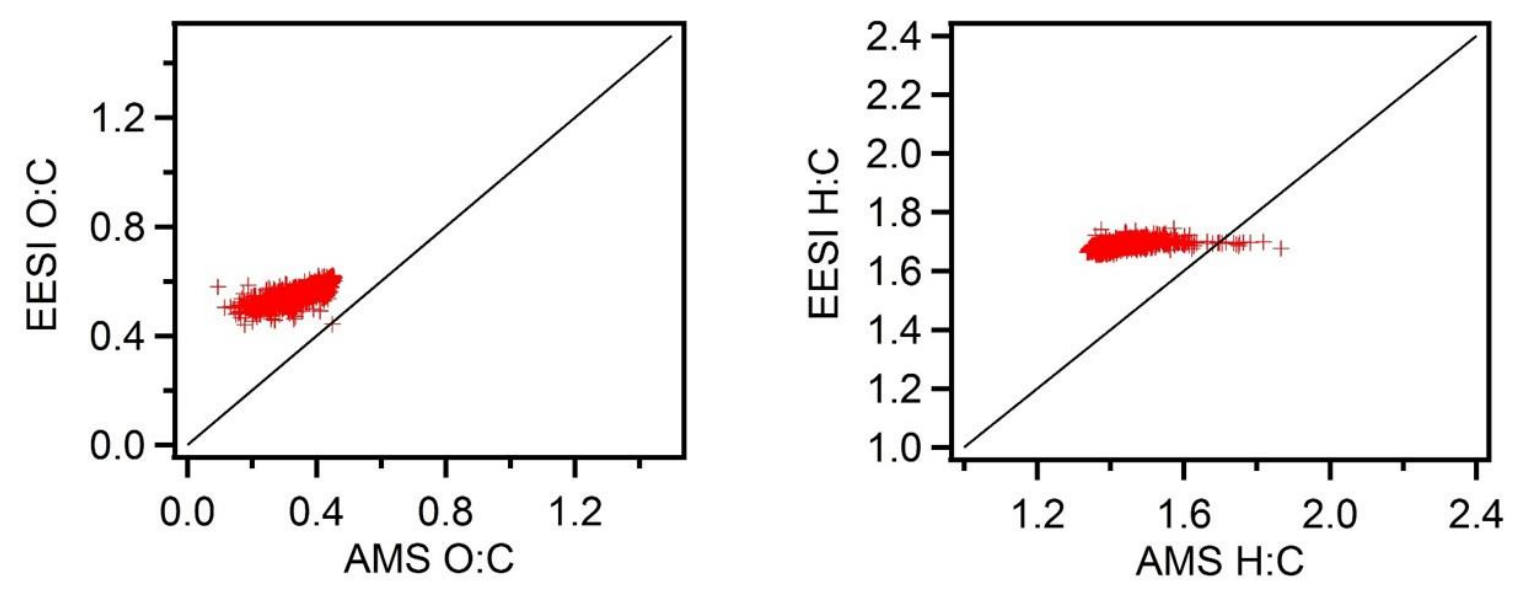

Figure S7. Atomic ratios for the total EESI and AMS signal. 